\title{
Does Trust Associate with Political Regime?
}

\author{
Sára Khayouti ${ }^{1}$, Hubert János Kiss ${ }^{1,2^{*}}$, Dániel Horn ${ }^{1,2}$ \\ ${ }^{1}$ Institute of Economics, Centre for Economic and Regional Studies (KRTK KTI), Tóth Kálmán u. 4., 1097 Budapest, Hungary \\ 2 Department of Economics, Corvinus University of Budapest, Fővám tér 8., 1093 Budapest, Hungary \\ * Corresponding author, e-mail: kiss.hubert@krtk.hu
}

Received: 11 January 2021, Accepted: 11 March 2021, Published online: 07 January 2022

\begin{abstract}
Since trust correlates with economic development and in turn economic development associates with political regime, we conjecture that there may be a relationship between trust and political regime. Without looking for any casual inference, we investigate if trust aggregated on the country level correlates with the country's political regime. Specifically, we are interested whether trust correlates positively with the level of democracy in cross-sectional observations. We analyse data on trust from 76 countries using the Global Preference Survey and investigate the correlations with five separate democracy indices (Polity2, Economist Intelligence Unit's Index of Democracy, Freedom House, MaxRange and Unified Democracy Score). We do not find any significant association, with or without taking into account other factors (e.g., regional location, economic development, geographic conditions, culture) as well. Trust does not correlate with cornerstones of democracy either, measured by five components of the EIU index. A robustness check using an alternative measure of trust from the World Values Survey reaches the same results. The present study supersedes the working paper version (Khayouti et al., 2020).
\end{abstract}

\section{Keywords}

economic development, political regime, trust

\section{Introduction}

Simmel (1950:p.326) claims that "trust is one of the most important synthetic forces within society". A testament to this statement is the empirical finding that trust associates with economic development. Knack and Keefer (1997), Whiteley (2000), Dincer and Uslaner (2010) and Beugelsdijk et al. (2004) provide evidence on the correlation between trust and national income (or economic growth), while Algan and Cahuc (2010) show that the relationship is causal. Regarding the mechanisms behind the previous findings, Zak and Knack (2001) offer theoretical and empirical support that trust affects the rate of investment, while Bjørnskov (2012) documents the effect of trust on schooling and the rule of law.

On the other hand, Acemoglu et al. (2019) claim that democracy has a significant positive effect on income. Weede (1996) suggests that the variance in growth rates is larger among autocracies than among democracies. Leblang (1996) claims that the political regime affects economic development indirectly through its commitment to property right.

If trust associates positively with economic development and at the same time political regime has a relationship with national income, then one may suspect that on average trust is higher in more democratic countries. In fact, many scholars have argued that trust is one of the main elements of social capital that in turn is necessary to have social integration, economic efficiency and democratic stability (Arrow, 1972; Coleman, 1988; Gambetta, 1988; Ostrom, 1990; Fukuyama, 1995; Putnam, 2000; Newton, 2001). Moreover, there are theories that suggest that democracy has an advantage in generating trust relative to non-democracies due to several reasons. For instance, Sztompka (1997) lists seven conditions that enhance trust in society and that are generally present in democracies, but often absent in non-democracies. The overarching theme behind the conditions is that they insure the citizens against potential breaches of trust, and they include the transparency of social organisations, the stability of social order, the accountability of power and the enforcement of duties and responsibilities, among others. In this study, we examine empirically if democracies indeed exhibit higher levels of trust, without focusing on any concrete channel through which the two are related. We briefly examine also if trust associates with specific elements of democracy. 
Rainer and Siedler (2009) is the study that is closest to ours. They show that shortly after reunification East Germans were significantly less trusting than their Western counterparts, suggesting that political regime and trust are associated. However, interestingly decades of democracy were not able to close the trust gap. They show that economic hardships explain why trust levels in the former East Germany did not converge to those in the West. We have data on trust, political regime and economic development for 76 countries that allow us to see:

1. if there is an association between political regime and trust, and

2. if economic development is behind the previous association (if there is any).

\section{Data}

Trust does not have a precise definition. It is often used as an umbrella term that includes a set of positive values as reciprocity, civility, respect, solidarity, or empathy. However, in surveys standard questions emerged to measure trust. An example is Falk et al. (2018) who measured several preferences worldwide, among them trust. More concretely, in their Global Preferences Survey respondents were asked if they assume that other people only have the best intentions (Likert scale, 0-10). This trust measure was validated (Falk et al., 2016), predicting trusting behaviour in incentivised trust games. We use this global trust survey and link it to measures of political regime.

We take five widely used indices of political regime for 2012 (the year that the Global Preference Survey was executed) that are freely available. The Polity2 dataset (Marshall et al., 2013) assigns to each country a score ranging from -10 (hereditary monarchy) to 10 (consolidated democracy). The EIU Democracy Index (Kekic, 2007) considers five dimensions of political regime (e.g., civil liberties and political participation) and combines the scores in each dimension into a final one that ranges between 0 and 10. The Freedom House's (FH) Freedom in the World index (Puddington, 2012) assigns 0-4 points to 25 separate indicators (e.g. political rights, civil liberties), yielding an aggregate score per country ranging between 0 and 100 . The MaxRange (MR) dataset (Rånge et al., 2015) is based on seven main criteria (e.g. political competition, electoral integrity and quality) resulting in an index that goes from 0 to 100. The Unified Democracy Score (UDS) (Pemstein et al., 2017) combines 10 existing indices using a Bayesian latent variable approach in a way that it is at least as reliable as the most reliable component measure.
We use different political regime indices because there is no consensual list with all the desired features that a fullfledged democracy should have. Hence, there is no perfect political regime index and a way to deal with this issue is to consider several such indices. We standardise these measures for our analysis, so that they can be compared intuitively without being influenced by their different ranges and averages. Pairwise correlation between the indices that we use ranges from 0.723 (MR vs. EIU) to 0.969 (EIU vs. UDS), all of them being significant at the $1 \%$ significance level.

\section{Findings}

Fig. 1 depicts the simple association between the Polity2 index and trust, while Fig. 2 contains the coefficient plots that also take into account other factors. Using other indices does not change the overall picture. The magnitude of correlation varies between -0.0297 (UDS) and -0.2286 (MR) and is significant only for MR at the 5\% significance level. Hence, most of the correlations fail to be significant, moreover all of them have a negative sign, contrary to our expectation. In Appendix A, we report the same figure with the other political regime indices (see Fig. 3-6 in Appendix A).

To gain a better insight, we carry out stepwise OLS regression analyses for each political regime index. The same regressions are run consistently, and we use coefficient plots to represent the results in a parsimonious way. Thick/thin lines indicate the confidence intervals of the effects at the $10 / 5 \%$ significance levels.

The dependent variable is always trust, aggregated on country level. Our first specification has only the given

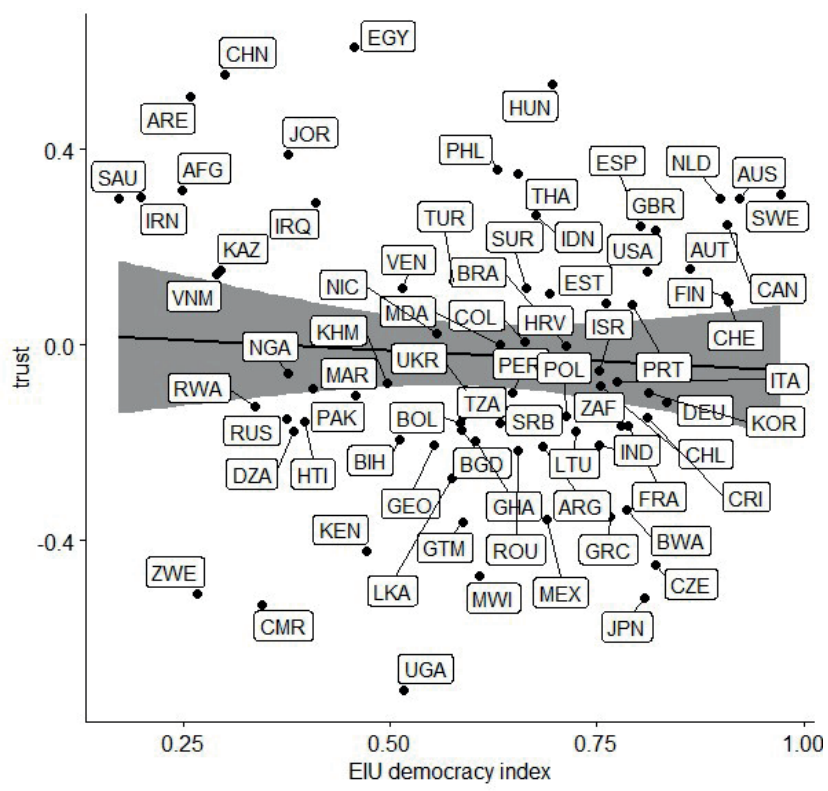

Fig. 1 The association between trust and the EIU democracy index (no additional controls added) 


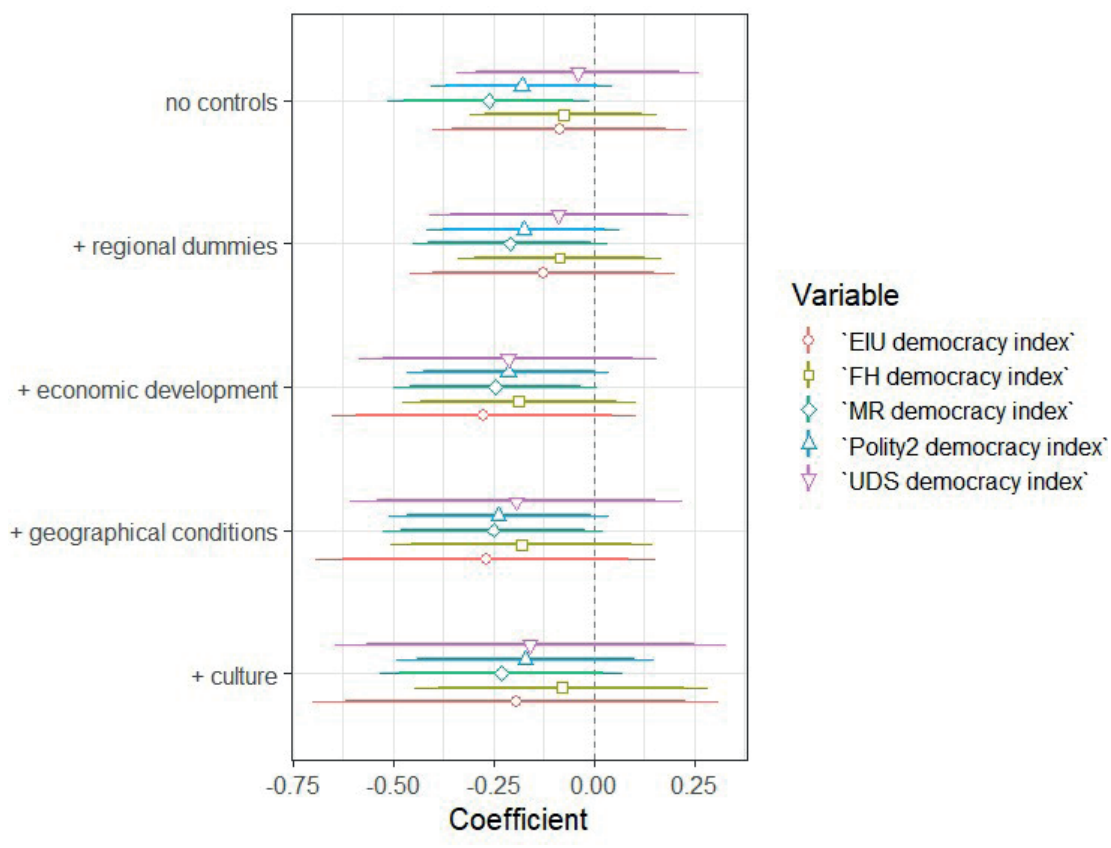

Fig. 2 Association between trust and political regime without and with controls, coefficient plots

political regime index (converted to a $0-1$ scale, higher values indicating more democracy) as regressor. Next, we add regional dummies as Falk et al. (2018) document regional disparities in trust. Subsequently, we also control for economic performance using GDP per capita (PPP) and unemployment rate, as economic development may be correlated both with trust and political regime. The fourth specification adds controls related to geographical conditions (average temperature, average precipitation, and distance to Equator) taken from Falk et al. (2018) as that study reports an association between these factors and trust. For the same reason, we also include controls for culture in the last specification, captured by the share of different religions in the population (based on data obtained from the Pew Research Center website).

As Fig. 2 indicates, contrary to our expectation all coefficients are negative and generally are insignificant. More concretely, 3 of our 5 indices (EIU, FH and UDS) fail to exhibit even marginal significance in any of the specifications, Polity 2 is marginally significant in one specification, while the MaxRange score is at least marginally significant in 4 of our 5 specifications. Importantly, in the most comprehensive specification none of the indices proves to be significant. We carry another analysis. The EIU index has five categories (electoral process and pluralism, functioning of government, political participation, political culture, civil liberties) for which scores are published. We run the same regressions as before to see if any of those categories associates with trust. We fail to see any consistent pattern, see Fig. 7 in Appendix B.

Overall, the data that we study suggest that trust and political regime do not associate. The question asked in the Global Preference Survey differs from the more widely used question in the World Value Survey ("Generally speaking, would you say that most people can be trusted, or that you can't be too careful in dealing with people?"), so one may wonder if this difference on how trust is measured affects the findings. Therefore, we carried out a robustness check and used the available data from wave 6 of the World Value Survey. In Appendix C, we present the findings of this robustness check that reaches the same conclusion (Fig. 8 in Appendix C).

\section{Conclusion}

Even though the extant literature - and our intuition suggests a positive correlation between trust and the level of democracy, we fail to find such association using the worldwide trust survey by Falk et al. (2018) and well-known political regime indices, such as the score of democracy from the Polity2 dataset, the Economist Intelligence Unit's Index of Democracy, the Freedom House's democracy index, MaxRange democracy score and Unified Democracy Score. The result does not change qualitatively, even if we take into account a wide range of controls (regions of the world, per capita GDP, temperature, precipitation, distance to equator and percentages of 
religion adherents). Moreover, if we investigate whether trust associates with elements of democracy, we are still unable to establish firm relationships. A robustness check has been conducted using a measure of trust from the World Values Survey, yet still the results contradict the

\section{References}

Acemoglu, D., Naidu, S., Restrepo, P., Robinson, J. A. (2019) "Democracy Does Cause Growth", Journal of Political Economy, 127(1), pp. 47-100.

https://doi.org/10.1086/700936

Algan, Y., Cahuc, P. (2010) "Inherited Trust and Growth", American Economic Review, 100(5), pp. 2060-2092. https://doi.org/10.1257/aer.100.5.2060

Arrow, K. J. (1972) "Gifts and Exchanges", Philosophy \& Public Affairs, 1(4), pp. 343-362. https://www.jstor.org/stable/2265097

Beugelsdijk, S., de Groot, H. L. F., van Schaik, A. B. T. M. (2004) "Trust and economic growth: a robustness analysis", Oxford Economic Papers, 56(1), pp. 118-134. https://doi.org/10.1093/oep/56.1.118

Bjørnskov, C. (2012) "How Does Social Trust Affect Economic Growth?", Southern Economic Journal, 78(4), pp. 1346-1368. https://doi.org/10.4284/0038-4038-78.4.1346

Coleman, J. S. (1988) "Social Capital in the Creation of Human Capital", American Journal of Sociology, 94, pp. S95-S120. https://doi.org/10.1086/228943

Dincer, O. C., Uslaner, E. M. (2010) "Trust and growth", Public Choice, 142(1-2), pp. 59-67. https://doi.org/10.1007/s11127-009-9473-4

Falk, A., Becker, A., Dohmen, T., Enke, B., Huffman, D., Sunde, U. (2018) "Global Evidence on Economic Preferences", The Quarterly Journal of Economics, 133(4), pp. 1645-1692. https://doi.org/10.1093/qje/qjy013

Falk, A., Becker, A., Dohmen, T. J., Huffman, D., Sunde, U. (2016) "The Preference Survey Module: A Validated Instrument for Measuring Risk, Time, and Social Preferences", Netspar Discussion Paper, No. 01/2016-003 https://doi.org/10.2139/ssrn.2725874

Fukuyama, F. (1995) "Trust: The Social Virtues and the Creation of Prosperity", Free Press, New York, NY, USA.

Gambetta, D. (ed.) (1988) "Trust: Making and Breaking Cooperative Relations", Blackwell, Oxford, UK.

Khayouti, S., Kiss Hubert, J., Horn, D. (2020) "Does trust associate with political regime?", No.: 13, CERS-IE WORKING PAPERS, Budapest, Hungary.

Kekic, L. (2007) "The Economist Intelligence Unit's index of democracy", [pdf] The Economist, London, UK, Available at: https:// www.economist.com/media/pdf/democracy_index_2007_v3.pdf [Accessed: 10 March 2021]

Knack, S., Keefer, P. (1997) "Does Social Capital Have an Economic Payoff? A Cross-Country Investigation", The Quarterly Journal of Economics, 112(4), pp. 1251-1288. https://doi.org/10.1162/003355300555475 assumption of positive relationship between trust and democracy. Further research is therefore needed, using various measures of trust, and exploring not only the correlation but the causal relationship between trust and political regime.

Leblang, D. A. (1996) "Property Rights, Democracy and Economic Growth", Political Research Quarterly, 49(1), pp. 5-26. https://doi.org/10.1177\%2F106591299604900102

Marshall, M. G., Gurr, T. R., Jaggers, K. (2013) "POLITYTM IV PROJECT: Political Regime Characteristics and Transitions, 18002016, Dataset Users' Manual" [pdf] Center for Systemic Peace, Vienna, VA, USA, Available at: https://www.systemicpeace.org/ inscr/p4manualv2016.pdf [Accessed: day month year]

Newton, K. (2001) "Trust, Social Capital, Civil Society, and Democracy", International Political Science Review, 22(2), pp. 201-214. https://doi.org/10.1177/0192512101222004

Ostrom, E. (1990) "Governing the Commons: The Evolution of Institutions for Collective Action", Cambridge University Press, Cambridge, UK. https://doi.org/10.1017/CBO9780511807763

Pemstein, D., Meserve, S. A., Melton, J. (2017) "Democratic Compromise: A Latent Variable Analysis of Ten Measures of Regime Type", Political Analysis, 18(4), pp. 426-449. https://doi.org/10.1093/pan/mpq020

Puddington, A. (2012) "Freedom in the world", [pdf] Freedom House, Washington, USA, Availabe at: https://freedomhouse.org/sites/ default/files/2020-02/FIW_2012_Booklet.pdf [Accessed: 10 March 2021]

Putnam, R. D. (2000) "Bowling Alone: The Collapse and Revival of American Community", Simon and Schuster, New York, NY, USA.

Rainer, H., Siedler, T. (2009) "Does democracy foster trust?", Journal of Comparative Economics, 37(2), pp. 251-269. https://doi.org/10.1016/j.jce.2008.09.003

Rånge, M., Wilson, M. C., Sandberg, M. (2015) "Introducing the MaxRange Dataset: Monthly Data on Political Institutions and Regimes Since 1789 and Yearly Since 1600", SSRN Electronic Journal, pp. 1-35. https://doi.org/10.2139/ssrn.2672775

Simmel, G. (1950) "The Sociology of Georg Simmel", The Free Press, New York, NY, USA.

Sztompka, P. (1997) "Trust, Distrust and the Paradox of Democracy" Wissenschaftszentrum, Berlin, Germany.

Weede, E. (1996) "Political regime type and variation in economic growth rates", Constitutional Political Economy, 7(3), pp. 167-176. https://doi.org/10.1007/BF00128160

Whiteley, P. F. (2000) "Economic Growth and Social Capital", Political Studies, 48(3), pp. 443-466. https://doi.org/10.1111\%2F1467-9248.00269

Zak, P. J., Knack, S. (2001) "Trust and Growth", The Economic Journal, 111(470), pp. 295-321. https://doi.org/10.1111/1468-0297.00609 


\section{Appendix A}

In this Appendix we represent the scatterplots between the political regime indices and trust.

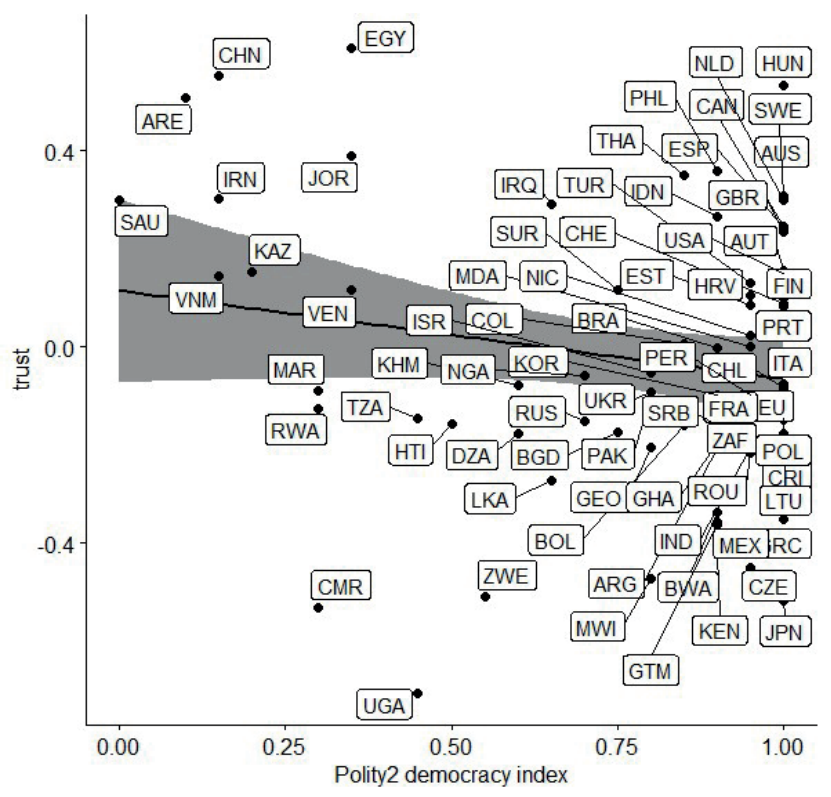

Fig. 3 The association between trust and the Polity 2 democracy index (no additional controls added)

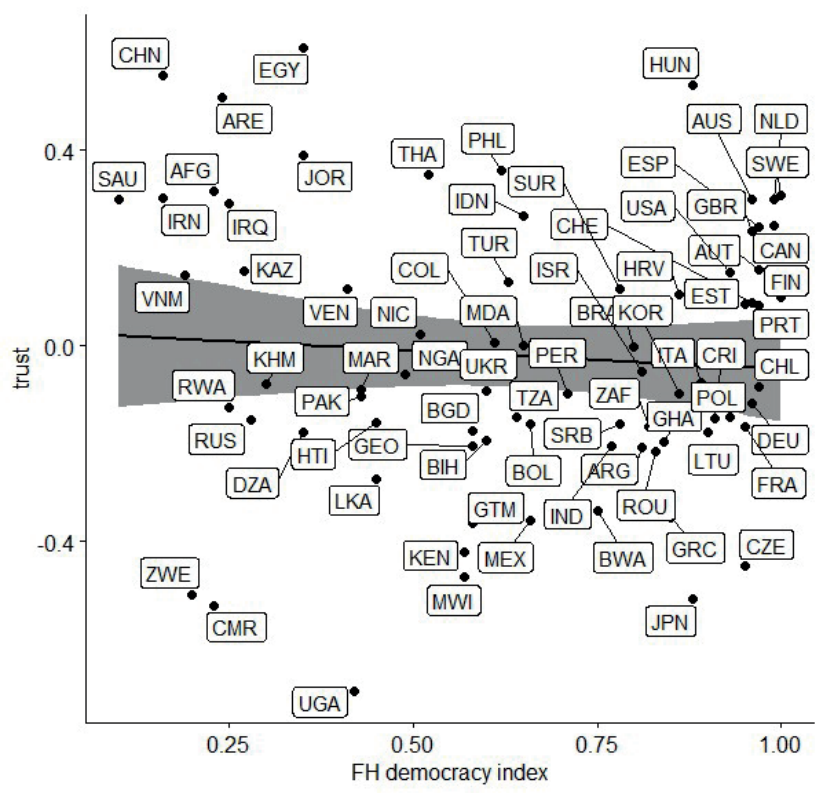

Fig. 4 The association between trust and the Freedom House democracy index (no additional controls added)

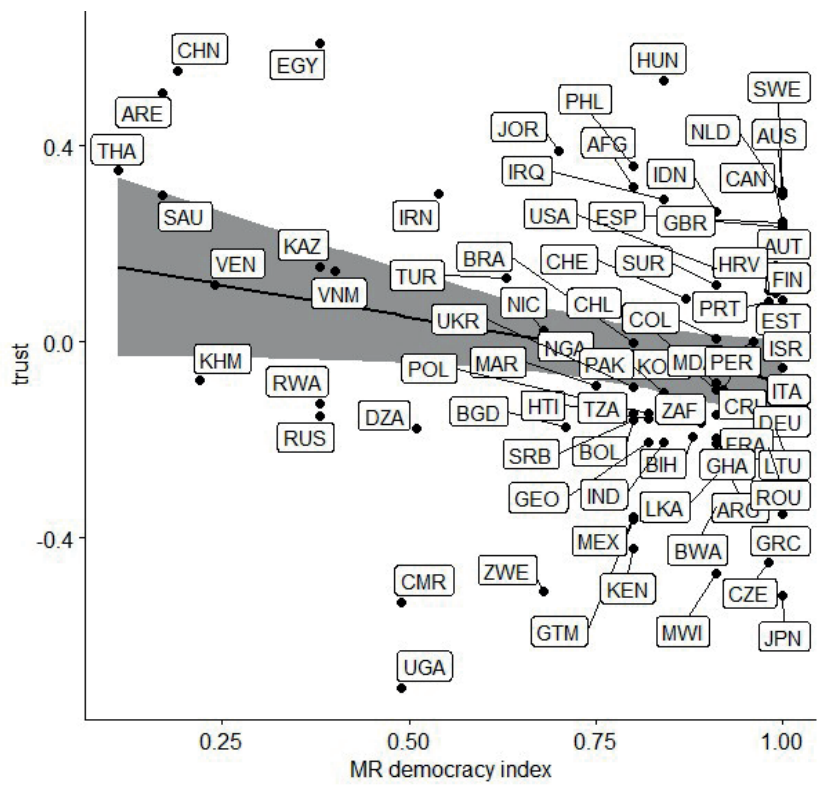

Fig. 5 The association between trust and the Max Range democracy index (no additional controls added)

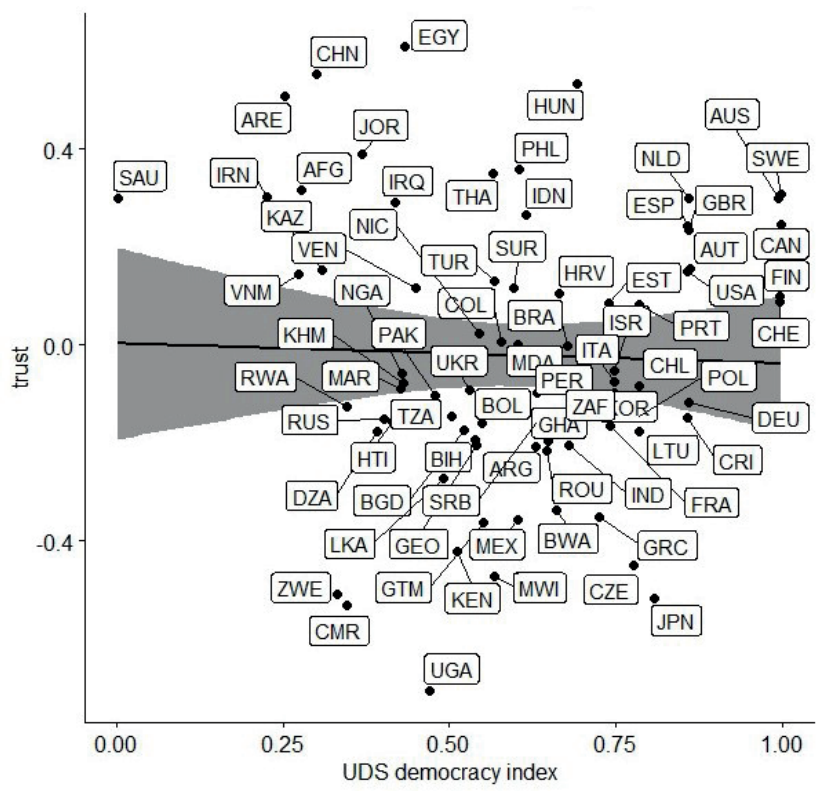

Fig. 6 The association between trust and the Unified Democracy Score democracy index (no additional controls added) 


\section{Appendix B}

In this Appendix, we run the same regressions as for Fig. 2, but not for different political regime indices. Here our aim is to see if building blocks of the EIU Democracy index associate with trust.

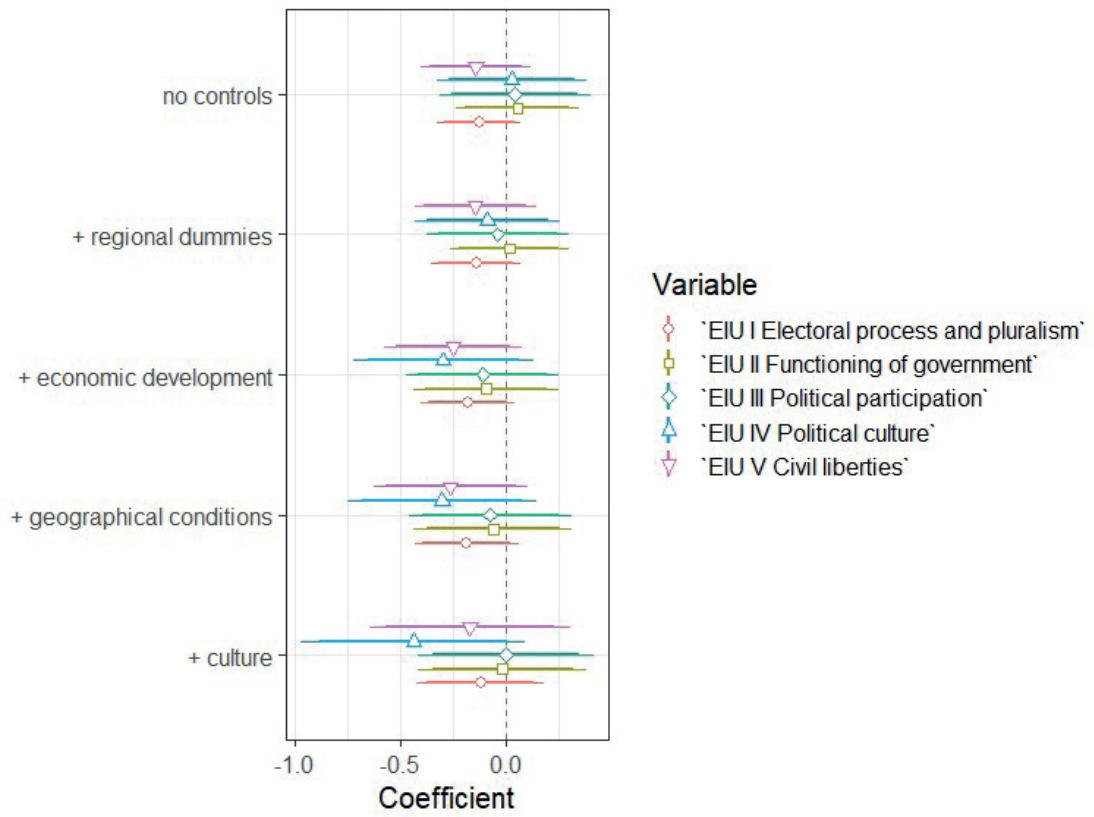

Fig. 7 Association between trust and components of the EIU index, coefficient plots

\section{Appendix C}

In this Appendix, we present a robustness check for the aforementioned results. We run similar regressions as for Fig. 2 limiting our attention to the specification without controls and specifications that contain variables related to economic development. We use the question on trust from the World Value Survey "Generally speaking, would you say that most people can be trusted, or that you can't be too careful in dealing with people?".

The coefficients of trust are generally insignificant (in line with Fig. 2). It is important to note, however, that there are available data only for 59 countries that may affect the precision of the estimates and present potential issues of selection.

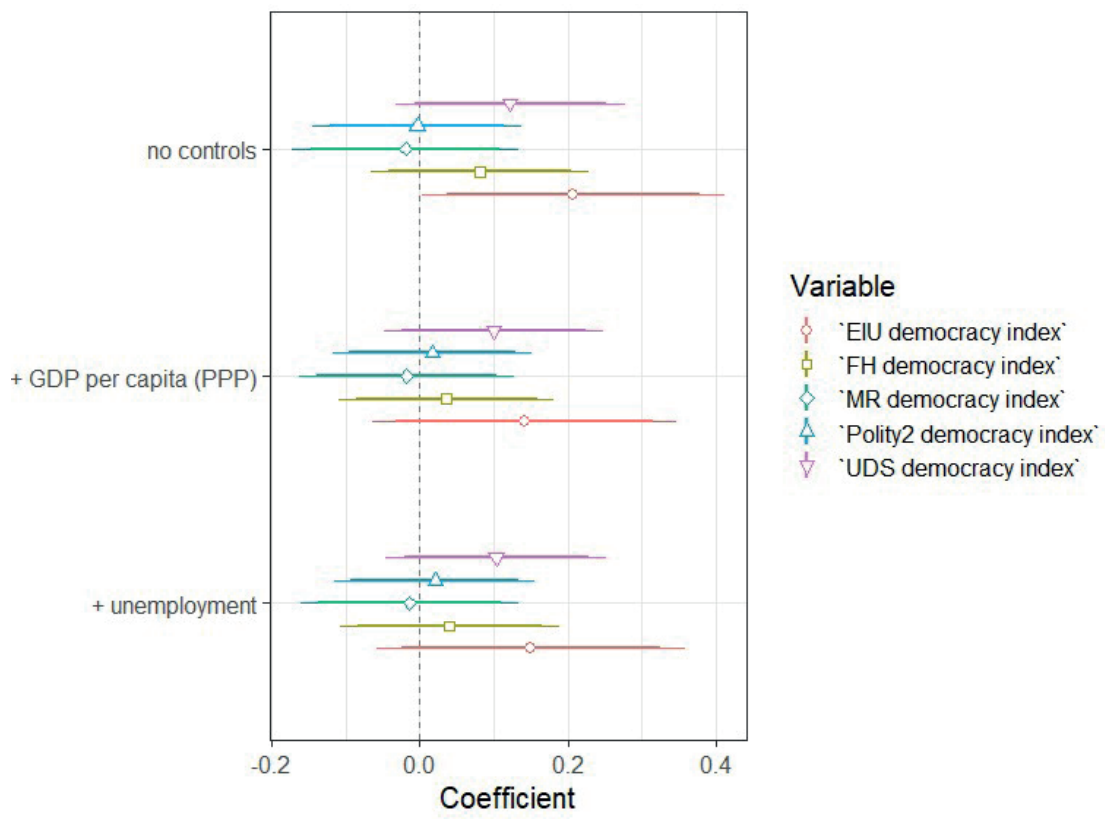

Fig. 8 Association between trust measured in the WVS and political regime without and with controls, coefficient plots 